\title{
ANALISIS CUSTOMER RESPONSE INDEX IKLAN HANDPHONE MEREK NEXIAN PADA PEMBACA MEDIA CETAK DI KOTA KUPANG
}

\author{
Made Susilawati \\ madesusilawati10@yahoo.co.id
}

\begin{abstract}
ABSTRAK
Tujuan penelitian ini adalah untuk menganalisis Customer Response Index (CRI) iklan handpone merek Nexian pada pembaca media cetak di Kota Kupang. Data yang dikumpulkan adalah data sekunder. Data dianalisis dengan menggunakan metode deskriptif kuantitatif. Hasil penelitian menunjukkan bahwa CRI iklan handphone merek Nexian pada media cetak (Pos Kupang dan Timor Express) di Kota Kupang diperoleh CRI 4,02\%. Dengan demikian, masih ada peluang sebesar 95,98\% CRI yang masih bisa diraih. Berdasarkan hasil CRI perusahaan perlu menerapkan strategi komunikasi yang lebih efektif agar mampu meningkatkan intentions lebih dari 30,88\% sehingga dapat meningkatkan CRI-nya yang dapat berpeluang meningkatkan niat membeli (intentions) handphone merek Nexian dan memungkinkan diikuti dengan tindakan membeli (action).
\end{abstract}

Kata Kunci: Iklan, Efektivitas Komunikasi, dan CRI

\section{Pendahuluan}

Dalam dunia periklanan modern, manajemen perusahaan pengiklan harus dapat membentuk produk yang diiklankan memiliki brand platform yang kuat dengan harga yang terjangkau dan mudah didapatkan dalam pasar sasaran. Merek produk harus dikomunikasikan dengan efektif agar dapat diterima sesuai dengan apa yang diharapkan perusahaan pengiklan produk.

Menurut Durianto, dk k (2003:47) secara umum komunikasi suatu merek memiliki tiga tujuan utama yaitu :

1. Membangun serta meningkatkan brand awareness.

2. Memperkuat, memperjelas, dan mempercepat pesan suatu merek.

3. Menstimulasi dan memotivasi target konsumen untuk melakukan aksi pembelian.

Lebih lanjut Durianto, dkk mengatakan bahwa seorang pemasar dapat mengukur efektivitas komunikasi yang dijalankannya melalui Customer Response Index (CRI) yang merupakan hasil perkalian antara awareness (kesadaran), comprehend (pemahaman konsumen), interest (ketertarikan), intentions (maksud untuk membeli), dan action (bertindak membeli). CRI menampilkan proses tindakan pembelian konsumen atas suatu merek produk yang berawal dari 
munculnya awareness (kesadaran) konsumen, yang pada akhirnya mampu mengarahkan konsumen pada action (tindakan membeli).

\section{Landasan Teori}

CRI menggambarkan respon konsumen terhadap suatu merek yang diawali konsumen mengetahui merek produk yang diiklankan, konsumen memahami informasi yang disampaikan, konsumen tertarik ingin mengetahui lebih jauh mengenai merek/produk yang diiklankan, ada niat ingin membeli, dan dilanjutkan dengan tindakan membeli produk yang diiklankan. Apabila hasil perhitungan CRI persentasenya besar menunjukkan tingginya respon konsumen terhadap suatu merek/produk (rich response). Namun bila hasil perhitungan CRI persentasenya kecil maka menunjukkan rendahnya respon konsumen terhadap suatu merek/produk (poor response).

Durianto, dkk (2003:50) mengatakan bahwa variasi rendahnya respon konsumen bisa bermacam-macam, antara lain:

1. Low Awareness, artinya kesadaran konsumen terhadap suatu merek sangat rendah; dengan kata lain, mind share (pangsa pikiran) konsumen sangat rendah. Hal ini biasanya disebabkan kesalahan strategi komunikasi pemasaran. Faktor penyebabnya bisa bermacam-macam, antara lain: pemilihan media iklan yang tidak tepat, frekuensi penayangan media iklan yang kurang banyak, dan eksekusi kreativitas media iklan yang kurang mengena.

2. Poor Comprehension, artinya pernahaman konsumen pada suatu merek sangat rendah. Fenomena ini biasanya disebabkan kesalahan strategi komunikasi pemasaran. Faktor penyebabnya biasanya adalah kurang cukupnya frekuensi penayangan iklan dan poor ad copy.

3. Low Interest, artinya ketertarikan konsumen pada suatu merek sangat rendah. Fenomena ini biasanya disebabkan lemahnya positioning produk. Faktor penyebabnya, antara lain: insufficient benefits, high price, dan poor ad copy.

4. Low Intentions, artinya niat konsumen untuk membeli masih sangat rendah. Hal ini biasanya karena kesalahan positioning produk. Faktor penyebabnya, antara lain: lemahnya nilai produk yang diterima konsumen, tidak tersedianya produk untuk dicoba (tester) oleh konsumen, atau konsumen merasa bahwa risiko pemakaian produk tersebut terlalu tinggi.

5. Low Purchase Level, artinya tingkat pembelian oleh target konsumen sangat rendah. Fenomena ini biasanya disebabkan masalah distribusi dan in-store promotion. Faktor penyebabnya, antara lain: tidak tersedianya produk tersebut di pasaran, sulit untuk m 
endapatkan produk tersebut di toko atau di supermarket pada saat konsumen hendak membeli, dan pelayanan instore yang kurang memadai.

Handphone saat ini sudah dianggap menjadi kebutuhan mendesak untuk mempercepat komunikasi dan aktivitas. Perusahaan handphone baik perusahaan nasional maupun perusahaan asing bersaing merebut pangsa pasar. Pasar handphone Indonesia yang selama ini hanya menawarkan produk Jepang dan Eropa, kini telah dibanjiri oleh handphone China. Salah satu produk handphone China yang gencar mempromosikan produknya adalah handphone merek Nexian. Promosi iklan dari handphone merek Nexian ini gencar dilakukan juga di Kota Kupang di berbagai media termasuk media cetak seperti Pos Kupang dan Timor Express.

\section{Metode Penelitian}

a. Jenis dan Variabel Penelitian, Indikator dan Skala Pengukuran

1. Penelitian ini termasuk jenis penelitian deskriptif yaitu penelitian dilakukan terhadap variabel mandiri tanpa membuat perbandingan atau menghubungkan dengan variabel lain.

2. Variabel yang digunakan dalam penelitian ini adalah analisis customer response index (CRI). CRI adalah alat untuk mengukur efektivitas komunikasi iklan suatu merek/produk terhadap respon konsumen yang diawali dengan konsumen mengetahui merek produk yang diiklankan, konsumen memahami informasi yang disampaikan, konsumen tertarik ingin mengetahui lebih jauh mengenai merek/produk yang diiklankan, ada niat ingin membeli, dan dilanjutkan dengan tindakan membeli produk yang diiklankan.

3. Indikator pengukur variabel adalah CRI $=$ awareness (kesadaran) $\mathrm{x}$ comprehend (pemahaman konsumen) $\mathrm{x}$ interest (ketertarikan) $\mathrm{x}$ intentions (maksud untuk membeli) $\mathrm{x}$ action (bertindak membeli).

4. Skala pengukuran variabel yang digunakan adalah skala rasio.

b. Populasi dan Sampel

1. Populasi dalam penelitian ini adalah pembaca Koran Pos Kupang dan Timor Express yang berada di Kota Kupang.

2. Sampel

Dari 100 responden yang diteliti 50 responden adalah pembaca Koran Pos Kupang dan 50 responden yang lain adalah pembaca Koran Timor Express. Sampel diambil secara. non-probabilitas dengan pendekatan judgment sampling. Sebagai judgement adalah pembaca Koran Pos Kupang dan Timor Express yang tinggal di Kupang. 
c. Sumber Data

Menurut sumbernya data yang digunakan dalam penelitian ini adalah :

1. Data primer adalah data yang diperoleh secara langsung yang perlu diolah lebih lanjut. Contohnya jawaban responden berdasarkan kuesioner.

2. Data sekunder adalah data yang diperoleh dari dokumen atau literatur yang berkaitan dengan penelitian. Contohnya informasi iklan handphone.

d. Teknik Pengumpulan Data

Teknik pengumpulan data dalam penelitian ini adalah :

1. Kuesioner adalah pengumpulan data dengan menyebarkan kuesioner yang meminta konsumen untuk menjawab pertanyaan baik isian maupun pilihan. Pertanyaan dalam kuesioner diarahkan untuk mencakup variabel-variabel riset, yaitu awareness (kesadaran), comprehend (pemahaman konsumen), interest (ketertarikan), intentions (maksud untuk membeli), dan action (bertindak membeli).

Kuesioner

1. Merek handphone apa yang paling anda ingat?

2. Selain merek handphone yang anda sebutkan di atas, merek handphone apa lagi yang anda ingat?
a.
b.
c.

3. Apakah anda mengenal handphone merek Nexian?
a. Ya, dan saya telah mencantumkannya dalam jawaban diatas
b. Ya, tetapi saya lupa mencantumkan dalam jawaban diatas
c. Tidak

(Kalau anda menjawab Tidak, abaikan semua pertanyaan selanjutnya)

4. Apakah anda mengerti pesan iklan handphone di koran?
a. Ya
b. Tidak

Kalau anda menjawab Tidak, mengapa anda tidak mengerti?

a. Iklan handphone Nexian jarang diiklankan 
b. Iklan handphone Nexian tidak jelas

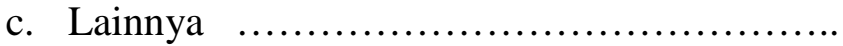

(Kalau anda menjawab Tidak, abaikan semua pertanyaan selanjutnya)

5. Apakah iklan handphone di koran dapat membuat anda tertarik pada handphone Nexian?
a. Ya
b. Tidak

Kalau anda menjawab Tidak, mengapa anda tidak tertarik?
a. Iklan handphone Nexian jarang diiklankan
b. Iklan handphone Nexian tidak menarik

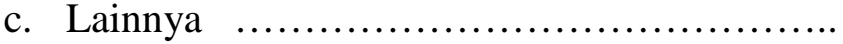

(Kalau anda menjawab Tidak, abaikan semua pertanyaan selanjutnya)

6. Apakah anda pernah berniat untuk membeli handphone Nexian?
a. Ya
b. Tidak

Kalau anda menjawab Tidak, mengapa anda tidak pernah berniat untuk membeli?
a. Sulit ditemukan pada counter-counter HP
b. Harganya mahal
c. Saya sudah setia pada satu merek
d. Adanya sikap atau pengaruh dari orang lain untuk tidak membeli

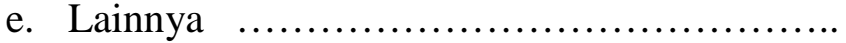

(Kalau anda menjawab Tidak, abaikan semua pertanyaan selanjutnya)

7. Apakah anda sudah membeli handphone Nexian?
a. Ya
b. Tidak

Kalau anda menjawab Tidak, mengapa anda belum membeli?
a. Sulit ditemukan pada counter-counter HP
b. Adanya sikap atau pengaruh dari orang lain untuk tidak membeli

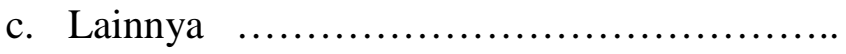

(Kalau anda menjawab Tidak, abaikan semua pertanyaan selanjutnya) 
2. Studi dokumentasi adalah data yang diperoleh dari dokumen atau literatur yang berkaitan dnegan penelitian.

\section{Hasil dan Pembahasan}

Identitas Responden

Responden dalarn penelitian ini adalah pembaca Koran Pos Kupang dan Timor Express di kota Kupang, dan target pasar handphone merek Nexian adalah pembaca yang tinggal di perkotaan. Riset berlangsung bulan Juni 2010, dan melibatkan 100 orang responden, 50 responden adalah pembaca Koran Pos Kupang dan 50 responden adalah pembaca Koran Timor Express yang mayoritas responden berusia 25-45 tahun (89\%), dengan tingkat pendapatan 3 - 5 juta rupiah $(83,5 \%)$. Dilihat dari segi pekerjaan 20,5\% responden adalah pelajar/mahasiswa, 45 $\%$ adalah pegawai/karyawan, 32,5\% adalah wiraswasta/pengusaha, dan 2\% adalah pekerjaan lainnya.

Dari data yang terkumpul, kemudian dilakukan pengukuran tingkat awareness, comprehend, interested, intentions, dan action untuk handphone merek Nexian. Setelah menghitung persentase keseluruhan aspek, akan diketahui besarnya CRI (Customer Response Index) yang merupakan hasil perkalian antara awareness, comprehend, interest, intentions, dan action. Selanjutnya berdasarkan hasil perhitungan persentase CRI dicari faktor penyebab tinggi/rendahnya respon konsurnen terhadap tingkat awareness, comprehend, interest, intentions, dan action untuk handphone merek Nexian.

Hasil Riset terhadap Brand Awareness

1. Top of Mind

\begin{tabular}{|c|l|c|r|}
\hline No & Merek Handphone & Jumlah Responden & Persentase (\%) \\
\hline 1 & Nokia & 25 & 25 \\
2 & Sony Ericson & 17 & 17 \\
3 & Siemens & 14 & 14 \\
4 & Samsung & 10 & 10 \\
5 & Motorola & 10 & 10 \\
6 & Nexian & 9 & 9 \\
7 & Blackberry & 8 & 8 \\
8 & LG & 7 & 7 \\
\hline & Total & 100 & 100 \\
\hline
\end{tabular}

Sumber : data olahan 
Nokia menduduki posisi top of mind, sedangkan merek Nexian berada di urutan keenam. Hal ini mungkin karena Nexian sangat gencar mempromosikan produknya melalui berbagai media. Namun kondisi ini menunjukkan merek Nexian walaupun masih baru di pasar namun mendapat respon cukup positif.

\section{Brand Recall}

\begin{tabular}{|c|l|c|r|}
\hline No & Merek Handphone & Jumlah Responden & Persentase (\%) \\
\hline 1 & Sony Ericson & 45 & 15.0 \\
2 & Nokia & 41 & 13.7 \\
3 & Motorola & 38 & 12.7 \\
4 & Nexian & 37 & 12.3 \\
5 & Blackberry & 30 & 10.0 \\
6 & Samsung & 26 & 8.7 \\
7 & LG & 24 & 8.0 \\
8 & Siemens & 23 & 7.7 \\
9 & ZTE & 5 & 1.7 \\
10 & Vitell & 5 & 1.7 \\
11 & K-Touch & 5 & 1.7 \\
12 & Gvon & 5 & 1.7 \\
13 & Mito & 4 & 1.3 \\
14 & Gstar & 3 & 1.0 \\
15 & Skybee & 1 & 0.3 \\
16 & Tiger & 1 & 0.3 \\
17 & XP & 1 & 0.3 \\
18 & Skyphone & 1 & 0.3 \\
19 & Dezzo & 1 & 0.3 \\
20 & Etouch & 1 & 0.3 \\
21 & IT & 1 & 0.3 \\
22 & CrossX & 1 & 0.3 \\
23 & NexCom & 300 & 0.3 \\
\hline & Total & & 100.0 \\
\hline & Sumber : data olahan & & \\
& & 1 & \\
\hline
\end{tabular}

Dari tabel brand recall dapat diketahui bahwa merek Sony Ericson merupakan merek yang paling sering disebut yaitu sebesar 15\%, sedangkan merek Nexian menernpati urutan keempat yaitu sebesar $12,3 \%$. 


\section{Brand Recognition}

\begin{tabular}{|l|c|c|}
\hline & Jumlah Responden & Persentase (\%) \\
\hline $\begin{array}{l}\text { a. Ya, dan saya telah mencantumkannya dalam } \\
\text { jawaban di atas }\end{array}$ & 48 & 48 \\
\hline $\begin{array}{l}\text { b. Ya, tetapi saya lupa mencantumkannya dalam } \\
\text { jawaban di atas }\end{array}$ & 50 & 50 \\
\hline c. Tidak & 2 & 2 \\
\hline Total & 100 & 100 \\
\hline
\end{tabular}

Pertanyaan butir (b) menunjukkan Brand recognition. Berdasarkan jawaban responden yang menjawab dengan pilihan jawaban butir (b) dapat diketahui brand recognition responden. Dari tabel jawaban responden di atas diketahul bahwa responden yang menjawab butir (b) adalah 50 responden atau 50\%. Dengan demikian, sebanyak 50\% responden yang harus diingatkan dalam pengenalan kesadaran. Responden yang tidak mengetahui keberadaan merek Nexian dapat dilihat dari jawaban responden yang memilih butir (c), yang berjumlah 2 responden atau $2 \%$. Jumlah responden yang sadar terhadap merek Nexian sebanyak 88 orang $(48+50$ orang) atau $98 \%[48 \%+50 \%)$.

Tabulasi Hasil No Comprehend

\begin{tabular}{|l|c|c|}
\hline & Jumlah Responden & Persentase (\%) \\
\hline a. Iklan handphone merek Nexian jarang diiklankan & 1 & 20 \\
\hline b. Iklan handphone merek Nexian tidak jelas & - & - \\
\hline c. Iklan tidak berhubungan dengan produk & - & - \\
\hline d. Tidak memberikan alas an & 4 & 80 \\
\hline \multicolumn{1}{|c|}{ Total } & 5 & 100 \\
\hline
\end{tabular}

Dari 98 responden yang sadar akan merek Nexian sebanyak 5 orang atau 5,10\% (5/98 x $100 \%$ ) tidak mengerti pesan iklan handphone merek Nexian di koran. Dari tabel di atas dapat diketahui faktor penyebab rendahnya pemahaman konsumen terhadap iklan handphone Nexian di koran. Jumlah responden yang mengerti pesan iklan handphone merek Nexian di koran hanya 93 orang (98 - 5 orang) atau 94.90\% (93/98 x 100\%).

Tingkat pemahaman konsumen terhadap iklan handphone merek Nexian di koran tinggi. Kondisi ini terjadi, karena materi iklan handphone merek Nexian menginformasikan produknya dengan jelas dan menarik perhatian pembaca koran. 
Tabulasi Hasil No Interested

\begin{tabular}{|l|c|c|}
\hline & Jumlah Responden & Persentase (\%) \\
\hline a. Iklan handphone merek Nexian jarang diiklankan & 3 & 12.00 \\
\hline b. Iklan handphone merek Nexian tidak menarik & 2 & 8.00 \\
\hline c. Iklan tidak berhubungan dengan produk & - & - \\
\hline d. Sudah setia pada satu merek & 9 & 36.00 \\
\hline $\begin{array}{l}\text { e. Tidak suka fitur/fasilitas handphone merek } \\
\text { Nexian }\end{array}$ & 9 & 36.00 \\
\hline f. Tidak memberikan alasan & 2 & 8.00 \\
\hline$\quad$ Total & 25 & 100 \\
\hline
\end{tabular}

Dari 93 responden yang mengerti pesan iklan handphone merek Nexian di Koran, sebanyak 25 orang atau 26,88\% (25/93 x 100\%) tidak tertarik merek Nexian. Dari tabel di atas dapat diketahui faktor penyebab rendahnya ketertarikan konsumen pada merek Nexian. jumlah responden yang tertarik pada merek Nexian berjumlah 68 orang (93 -25 orang) atau 73,12\% (68/93x100\%). Sales promotion tools digunakan untuk membuat konsumen tertarik, salah satu cara yang dilakukan adalah paket harga (price pack) dan penambahan fitur/fasilitas.

Tabulasi Hasil No Intentions

\begin{tabular}{|l|c|c|}
\hline & Jumlah Responden & Persentase (\%) \\
\hline a. Sulit ditemukan pada counter-counter HP & 2 & 9.52 \\
\hline b. Harganya mahal & - & - \\
\hline c. Sudah setia pada satu merek & 14 & 66.67 \\
\hline d. Adanya sikap atau pengaruh dari orang lain & 5 & 23.81 \\
\hline Total & 21 & 100 \\
\hline
\end{tabular}

Dari 68 responden yang tertarik pada merek Nexian, sebanyak 21 orang atau $30.88 \%$ $(21 / 68 \times 100 \%)$ belum berniat untuk membeli handphone merek Nexian. Dari tabel jawaban responden di atas dapat diketahui faktor penyebab rendahnya niat konsurnen untuk membeli handphone merek Nexian. Jurnlah responden yang sudah berniat untuk membeli handphone merek Nexian hanya 47 orang (68 - 21 orang) atau 69,12\% (47/68 x 100\%).

Beberapa responden tidak berniat untuk membeli handphone merek Nexian karena sulit ditemukan pada counter-counter penjualan handphone. Beberapa responden yang tidak berniat untuk membeli handphone merek Nexian karena sudah setia pada satu merek. Apabila seorang konsumen handphone sudah merasa cocok dengan suatu merek handphone, biasanya konsumen tersebut akan sulit untuk beralih ke handphone merek lain. 
Tabulasi Hasil No Action

\begin{tabular}{|l|c|c|}
\hline & Jumlah Responden & Persentase (\%) \\
\hline a. Sulit ditemukan pada counter-counter HP & 5 & 13.16 \\
\hline b. Belum mau mencoba merek baru & 16 & 42.11 \\
\hline c. Tidak suka fitur/fasilitas HP merek Nexian & 17 & 44.74 \\
\hline Total & 38 & 100 \\
\hline
\end{tabular}

Dari 47 responden yang sudah berniat untuk membeli handphone merek Nexian sebanyak 38 orang atau 80,85\% (38/47x100\%) belum membeli handphone merek Nexian. Dari tabel di atas dapat diketahui faktor penyebab rendahnya tingkat pembehan handphone merek Nexian. Responden yang sudah membeli handphone merek Nexian hanya 9 orang (47-38 orang) atau $19,15 \%(9 / 47 \times 100 \%)$.

Beberapa responden yang belum membeli handphone merek Nexian disebabkan sulitnya ditemukan handphone merek Nexian di counter-counter handphone (HP), belum mau mencoba merek baru, dan tidak suka fitur/fasilitas handphone merek Nexian. Hal ini mungkin karena perusahaan kurang memperhatikan saluran distribusi untuk handphone merek Nexian, atribut/fasilitas handphone dan masih takut mencoba merek baru.

Hasil Pengukuran CRI Handphone Merek Nexian

1. Respon konsumen yang action $=$ aware $x$ comprehend $x$ interested $x$ intentions $x$ action. Besarnya $C R I=98 \% \times 94,90 \%$ x 73,12\% x 69,12\% x 19,15\%=9\%. Responden yang sampai pada tahap membli handphone merek Nexian ada 9\%, artinya masih ada peluang sebesar $81 \%$ $C R I$ yang masih bisa diraih. Dari hasil analisis CRI terhadap handphone merek Nexian, komunikasi iklan Nexian ternyata masih belum efektif. Faktor dominan yang menyebabkan rendahnya CRI adalah banyaknya konsumen yang tidak memahami iklan Nexian (poor comprehension).

2. Respon konsumen yang tidak action $=$ aware $x$ comprehend $\mathrm{x}$ interested $x$ intentions $x$ no action.

Besarnya respon konsurnen yang tidak action $=98 \% \times 94,90 \% \times 73,12 \% \times 69,12 \% \times 80,85 \%$ $=38 \%$. Responden yang pernah berniat untuk membeli handphone merek Nexian, tetapi belum membeli handphone merek Nexian berjumlah $38 \%$.

3. Respon konsurnen yang tidak intentions $=$ aware $\mathrm{x}$ comprehend $\mathrm{x}$ interested $\mathrm{x}$ no intentions. Besarnya respon konsumen yang tidak intentions $=98 \% \times 94,90 \% \times 73,12 \% \times 30,88 \%=21 \%$. 
Responden yang tertarik pada merek Nexian, tetapi belum berniat untuk membeli handphone merek Nexian berjumlah $21 \%$.

4. Respon konsumen yang tidak interested $=$ aware $x$ comprehend $\mathrm{x}$ no interested. Besarnya respon konsumen yang tidak interested $=98 \% \times 94,90 \% \times 26,88 \%=25 \%$.

Responden yang mengerti pesan iklan handphone merek Nexian di koran, tetapi tidak tertarik pada merek Nexian berjumlah $25 \%$.

5. Respon konsumen yang tidak comprehend $=$ aware $X$ no comprehend. Besarnya respon konsumen yang tidak comprehend $=98 \%$ x 5,1\% $=49,98 \%$. Responden yang sadar terhadap merek Nexian, tetapi tidak mengerti pesan iklan handphone merek Nexian di koran berjumlah $49,98 \%$.

6. Responden yang unaware berjumlah $2 \%$.

MODEL CRI

CRI

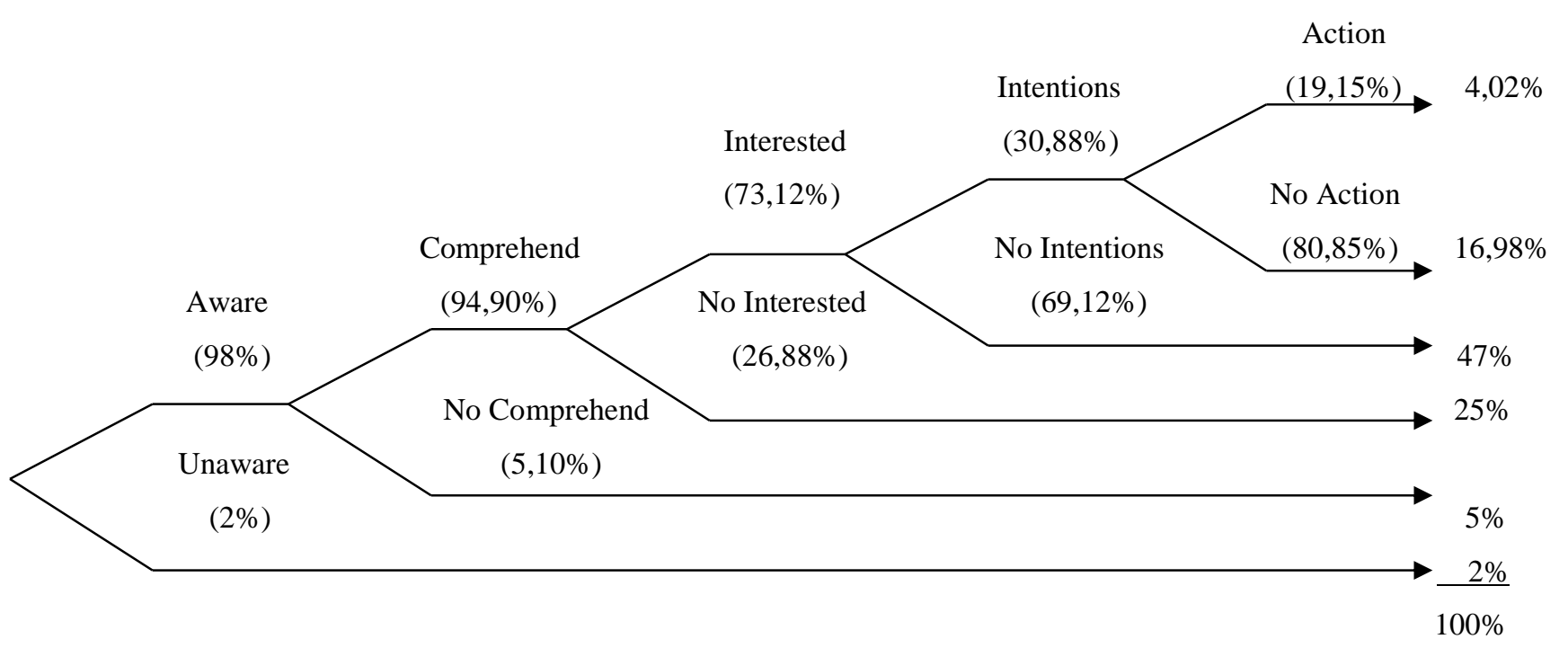

Berdasarkan hasil perhitungan CRI tersebut diatas diperoleh tingkat awareness sebesar $98 \%$, comprehend $94,90 \%$, interested $73,12 \%$, intention $30,88 \%$, dan action $19,15 \%$, maka CRI-nya adalah 4,02\%. Dengan demikian, masih ada peluang sebesar 95,98\% CRI yang masih bisa diraih. Kehilangan 95,98\% CRI itu disebabkan:

1. Yang tidak action sebesar $80,85 \%$ menyebabkan suatu merek kehilangan respon konsumen sebesar $16,98 \%$. 
2. Yang tidak intention sebesar $69,12 \%$ menyebabkan suatu merek kehilangan respon konsumen sebesar $47 \%$.

3. Yang tidak interested sebesar $26,88 \%$ menyebabkan suatu merek kehilangan respon konsumen sebesar $25 \%$.

4. Yang tidak comprehend sebesar 5,10\% menyebabkan suatu merek kehilangan respon konsumen sebesar $5 \%$.

5. Yang unaware sebesar $2 \%$ menyebabkan suatu merek kehilangan respon konsumen sebesar $2 \%$.

Oleh karena itu, apabila seorang pemasar dengan strategi komunikasi yang efektif mampu meningkatkan intentions dari 30,88\% menjadi lebih besar maka CRI (improved)-nya akan meningkat yang dapat berpeluang meningkatkan niat membeli handphone merek Nexian dan memungkinkan diikuti dengan tindakan membeli (action).

\section{Simpulan}

Iklan merupakan alat pemasaran perusahaan untuk menginformasikan produknya agar dapat diterima target market sesuai apa yang diharapkan perusahaan dalam upaya meningkatkan market share. Iklan harus dikomunikasikan dengan efektif agar dapat membentuk brand platform sesuai positioning produk yang diharapkan. Alat yang digunakan untuk menganalisis efektivitas komunikasi iklan terhadap respon konsumen adalah Customer Response Index (CRI) yang merupakan hasil perkalian antara awareness (kesadaran), comprehend (pemahaman konsumen), interest (ketertarikan), intentions (maksud untuk membeli), dan action (bertindak membeli). Alat yang digunakan untuk menganalisis efektivitas komunikasi iklan terhadap respon konsumen adalah Customer Response Index (CRI) yang merupakan hasil perkalian antara awareness (kesadaran), comprehend (pemahaman konsumen), interest (ketertarikan), intentions (maksud untuk membeli), dan action (bertindak membeli).

Hasil penelitian menunjukkan bahwa CRI iklan handphone merek Nexian pada media cetak (Pos Kupang dan Timor Express) di Kota Kupang diperoleh tingkat awareness sebesar 98\%, comprehend $94,90 \%$, interested $73,12 \%$, intention 30,88\%, dan action 19,15\%, maka CRI-nya adalah 4,02\%. Dengan demikian, masih ada peluang sebesar 95,98\% CRI yang masih bisa diraih. Berdasarkan hasil CRI perusahaan perlu menerapkan strategi komunikasi yang lebih efektif agar mampu meningkatkan intentions lebih dari 30,88\% sehingga dapat meningkatkan CRI-nya yang 
dapat berpeluang meningkatkan niat membeli (intentions) handphone merek Nexian dan memungkinkan diikuti dengan tindakan membeli (action).

\section{Daftar Pustaka}

Darmadi Durianto, dkk. 2003. Invasi Pasar dengan Iklan yang Efektif. Jakarta: PT. Gramedia Pustaka Utama.

David W. Cravens. 1996. Pemasaran Strategis. Jakarta: Penerbit Erlangga.

Philip Kotler. 1997. Manajemen Pemasaran: Analisis, Perencanaan, Implementasi dan Kontrol. Jakarata: PT. Prenhallindo.

Sugiyono. 2004. Metode Penelitian Bisnis. Bandung: Penerbit Alfabeta.

Suwarsono. 1996. Manajemen Stratejik. Yogyakarta: UPP AMP YKPN.

Zulian Yamit. 2002. Manajemen Kualitas Produk \& Jasa. Yogyakarta: Penerbit Ekonisia. 